ninth. The arerage time in the hospital was six weeks, gifter which the children were sent to the convalescent home for three weeks.

In conclusion, in cases in which resection was performed, the mortality in the above series of cases was 11 per cent., for children under three years of age 12 per cent., and for double empyemata 285 per cent. If these figures be compared with those given in a recent number of THE LANCET ${ }^{1-}$ viz., 20 per cent. in all cases, 50 per cent. in cases under three, and 84 per cent. for double empyemata-I think they show that a definite advantage is gained by resection of one or more ribs.

Airlie-gardens, Campden-hill, W.

\section{A CASE OF PERFORATED GASTRIC ULCER; GASTRORRHAPHY; RECOVERY.}

\section{BY HASTINGS GILFORD, F.R.C.S. ENG;}

THE patient in this case was a married woman twentymine years of age, who first showed symptoms indicative of the presence of a gastric ulcer eight years ago, when she romited blood twice; but, though she has been subject to occasional dyspepsia of an indefinite nature for more than eleven years, she has until recently had no marked pain or return of vomiting. I have known her for five years, during which period I have treated her at times for anæmia and mild flatulent dyspepsia, but I did not suspect the presence of a gastric ulcer until December, 1892, when she suffered from vomiting and epigastric pain. The vomiting appeared to bear no relation to the ingestion of food, and the vomit was free from blood; but, while pressure over the greater part of the abdomen gave rise to no pain, at one spot, which conld be covered with a shilling, the pressure of the finger cansed acute pain. I diagnosed gastric ulcer, advised her regarding her diet, and prescribed pills containing bismuth and creasote, but did not see her again until the ulcer perforated. I subsequently heard that she had improved so much that she did not consider it necessary to continue the treatment, and that she remained well until April 10th, 1893, when she bad a return of the pain and romited once. She was better on the following day, but the pain still troubled her occasionally. It was not induced by eating, but, on the contrary, was relieved by taking food. On June 22 nd, at $10 \mathrm{~A}$. M., after a breakfast at $8.30 \mathrm{~A}$. M. of cold mutton and bread and butter, she was bending over, washing her baby, when she felt a sudden agonising pain a aittle above and to the left of the umbilicus. She and the baby were alone in the house at the time, but she succeeded with difficulty in walking downstairs to get a neighbour to come for me. When I saw her at $10.30 \mathrm{~A}$ ir. she was lying in bed moaning with pain, which she referred to the middle and lower end of the sternum, and especially to the shoulder of each side. Respiration was mainly thoracic and was so increased by deep breathing that she dreaded to take a sufficient breath and suffered from dyspnoea in consequence. As she answered questions her hands involuntarily went to ber shoulders, the arms being crossed over the chest, and she cried out with pain. Pain in the abdomen had been slight since the beginning and was referred to the epigastric and left hypochondriac regions, and, while the abdominal muscles were rigid and were sensitive to pressure, the rigidity and tenderness were most pronounced in the same areas. Pain on pressure, moreover, was referred less to the abdomen than to the sternum and shoulders. The features were not shrunken, and there was no coldness of the extremities. She felt sick, but did not retch or vomit until half an hour after I had left her. The temperature was $96.8^{\circ} \mathrm{F}$, and the pulse 68 , regular, and of normal size and tension. I diagnosed perforation of a gastric ulcer and injected twenty minims of a solution of opium beneath the skin, greatly to the relief of her pain and breathing. The injection had to be repeated twice in the course of the day. The pulse-rate gradually rose, until at 6 P.M. it was 104, while the temperature was $101^{\circ}$. Dr. Moody-Ward saw ber with me late in the afternoon and concurred with my opinion that laparotomy was advisable. The operation, therefore, took place at 6.30 P. M., Dr. Abram kindly giving chloroform. An incision three inches and $a$ half in length was made in the middle line, starting half an inch from the ensiform cartilage. After the linea alba had been cut through, the subperitoneal fat and fascia projected like a bladder between the lips of the wound, and on puncturing it gas escaped, together with peritoneal fluid and stomach contents. On introducing the finger into the wound it almost immediately ran into the open ulcer, which was situated on the anterior surface, apparently near the middle. It was too small to admit of the introduction of the finger, but its $\epsilon$ dges were so brittle that the finger could be forcibly pushed in without difficulty by splitting the callous adjacent surface of the stomach. The edge of the ulcer appeared to be quite half an inch thick. The interior of the stomach was first explored for other ulcers, but with a negative result, and the margins of the perforation were then excised. Ten silkworm gut sutures were next introduced through the whole thickness of the stomach, including the mucous membrane. This material was used because it was evident that catgut would not be sufficiently durable, and silk appeared inadmissible from its greater liability to conduct septic matter along its threads. The number of sutures was necessitated by the length of the wound, which was about two inches, by the extreme brittleness of its tissue, and by the difficulty experienced in bringing the indurated edges together. Two sutares cut through while the others were being put in, and required to be replaced. Finally, when the wound had been firmly closed, a tabe was passed into the stomach, and water was poured into it through a funnel, in order to test the efficiency of the sutures. As no water escaped, the abdominal cavity was well irrigated with boiled water and the wound closed, a bulbous glass drainagetube being first passed through, so that its bulbous extremity rested on the closed ulcer.

On the second day after the operation, when the wound was dressed, there was very little watery discharge, but the tube had slipped along the lesser curvature until it was parallel with the external wound. As it could not be readily replaced it was taken out. The bowels acted loosely seren times in the night, and at 11.30 A.M. she passed urine for the first time for twenty-four hours and a half. She was fed during the next seven days with peptonised milk enemata, varied occasionally with beef-tea or raw meat, six ounces of which were given every four to six hours. On the ninth day after the operation the temperature, which had been normal for nearly forty-eigbt hours, began to rise, and varied between the extremes of $99.4^{\circ}$ and $100.5^{\circ}$ for the next five days. The wound suppurated, and she looked haggard and was very depressed. These symptoms indicated to me the presence of pus within the abdominal cavity and the necessity for a return to stomach feeding. Peppermint-water was first given in small and repeated doses, and on the tenth day after the operation two tablespoonfuls of peptonised milk and one of beef jelly were given every hour. Three days later she had advanced to oysters and farinaceons diet. On the fourteenth day after the operation she passed a motion which was said to be capped with pus, but through inadvertence it was thrown away before I saw it. I thought it probable that undigested mill had been mistaken for pus, for the patient felt no indication of an abscess having burst; the temperature was not affected, and no pus was found in the next motion passed. When, therefore, on the seventeenth day after the operation the temperature rose to $103^{\circ}$ and the pulse to 132 , and her features became anxions, sunken, and haggard, I thought it would be advisable to give chloroform and explore the abdomen in the neighbourhood of the incision with a needle; but fortunately, before carrying out this intention, I got Dr. Moody-Ward to see her, and he advised waiting until the temperature again rose to $103^{\circ}$. The next night at $130 \mathrm{~A}$ M. she was suddenly roused from sleep by a sudden sharp pain a little above and to the left of the umbilicus, and almost immediately afterwards called out for the bed-pan. A pale, loose, highly offensive motion was then passed, evidently composed principally of pus, and three other motions of a similar character were subsequently passed during the day. The temperature rapidly fell and two days afterwards was below normal, where it remained. She speedily improved in general condition and three weeks after the operation was sitting up in a chair. During the year which has since elapsed she has increased in flesh and has remained free from dyspeptic trouble. During the first three months of that time the thickened area of the healed alcer and the ends of the sutures could be plainly felt through the abdominal walls, but no sign of them can now be detected. 
Kemarks.-One of the most interesting features of this case was the absence of those symptoms which are usually considered to be characteristic of gastric ulcer and of its perforation. Thus, in the first place, the diagnosis of gastric ulcer rested almost solely upon the presence of a tender spot over the stomach area, for, though helped by the history of vomiting of blood many years before, this assistance was counterbalanced by the fact of the relief of pain by taking food. But this diagnosis was felt to be so sure that the symptoms which subsequently arose were at once referred to their right source. These symptoms, again, were by no means such as are usually laid down in text-books as indications of perforation of a gastric ulcer. The features and expression were not obviously altered, and nothing could be gathered from the character of the pulse and temperature. Pain was almost solely thoracic and was by no means so acute or attended with such shock as in other cases that have come under my notice. Thus in one instance, when perforation took place, the patient fell down in the street and was quite unable to walk, even with assistance, though her house was only a few yards off. In another case, which came under the observation of Dr. W. J. Maurice of Reading, a servant girl was found dead on the stairs of her master's house, and it was not until a post-mortem examination had been made that the cause of death was discovered, for she had complained of no suggestive symptoms daring life. I believe that the above is the first reported case in which the edges of the ulcer have been excised. It seems to me to be of great importance that the edges should be freshened in this way if possible, not only in order to obtain speedier union, but for purposes of cleanliness, as the edges must of necessity be so septic as to be difficult to disinfect by ordinary methods. Much, however, must depend upon the vascularity of the parts. To the same end it also appears of importance that the wound should, if the condition of the patient permit, be ascertained to be secure against leakage of gas or liquid by the use of the stomach tube. Since the publication of wy last case of this kind ${ }^{1}$ sixteen other instances have been lecorded. In Mr. Warrington Haward's case ${ }^{2}$ death took place from secondary abdominal abscess in six weeks. Dr. Stirling, ${ }^{3}$ Mr. Haslam, ${ }^{4}$ Mr. Godlee, ${ }^{5}$ and Mr. Pepper did not succeed in saving their patients. Of three cases in the practice of Dr. Maclaren ${ }^{7}$ one was a success.

In Dr. Anson's ${ }^{8}$ case, which was unsuccessful, a five-inch incision was first made in the median line and was subsequently extended at right angles through the rectus. This method, which I have tried, permits of the freest possible exposure of the whole of the surface of the stomach. The greater part of the organ can, indeed, be dragged, without difficulty, out of the wound, so that a perforation in any part of its surface may be dealt with with comparative ease. It was the method employed by Kriege ${ }^{9}$ for a perforation $3 \mathrm{~cm}$. from the cardiac end, which terminated successfully. Healso gives details of another case, in which an incision was made from the xiphoid cartilage to within a hand's-breadth of the pubes, and a transverse one cut to the left, and in which the patient died. More recently Mr. Morse ${ }^{10}$ has reported a case which recovered, and $\mathrm{Mr}$. Herbert Page ${ }^{11}$ two others which were unsuccessful. Dr. Maurice, at a meeting of the Reading Pathological Society, has also lately given details of a case which was nearly successful, the patient succumbing on the eighth day. A post-mortem examination revealed no sufficient cause for death. Of the twenty-seven instances of operation for the treatment of perforated gastric ulcer that I have been able to find recorded, and have mentioned in this and in a previous paper, six have recovered-viz, Mr. Taylor's, Mr. Barling's, Kriege's, Mr. Morse's, Dr. Maclaren's, and the above. When one considers that the extravasation of the contents of the stomach into the general peritoneal cavity has, until lately, been regarded as almost of necessity resulting in death, these results of operative treatment cannot be regarded as otherwise than encouraging.

Rsading.

Brit. Med. Jour., 1893, p. 944

Ibid., 1893, p. 952.

3 Austral. Med. Jour, 1893, p. 281.

4 Brit. Med. Jour., Nov. 11th, $1893 . \quad 5$ Ibid., March 17th, 1884 Ibid. Ibid.

8 The LANCET, March 4th, 1893.

9 Berliner Klinische Woch ${ }^{2}$ schrift, December, 1892.

10 The Lancet, March 17th, 1894

11 The Lancet, March 24th, 1804

\section{NOTE ON THE ETIOLOGY OF GRAVESS} DISEASE.

By D. R. PATERSON, M.D. Edin., M.R C.P. LoNd

PHYSICIAN TO THE HOSPITAL FOR SEAMEN ; PATHOLOGIST TO THE CARDIFF INFIRMARY.

THW influence of depressing emotions and prolonged bodily effort on the genesis of Graves's disease has received ample recognition. Patients not infrequently attribute the onset of their illness to grief or fright, or overstrain from some ardnons exertion, and the same factor may come into play in bringing on recurrence of the malady after apparent cure. Whether these causes suffice to start the affection in the first instance is not quite clear, but there is no donbt of their power to hasten the appearance of the more prominent symptoms. This is well shown by a case at present under my care, which I may be allowed to quote, as it illustrates another point to which I shall refer later. A girl seventeen years of age came under treatment in June of last year for enlarged tonsils. She exhibited some tremor and agitation, which increased readily on excitement. The tonsils having been removed under chloroform, two weeks later the patient presented a slight fulness of the middle lobe of the thyroid, which had just come on ; prominence of the eyeballs was barely noticeable, and, according to the patient's statement, the trembling nor extended to the legs. Ten days later the heart had increased in frequency, and at present all the symptoms of Graves's disease are in evidence. Inquiry elicited that for eighteen months the patient bad been subject to attacks of tremor, which occasionally interfered with the power of writing and had latterly been more frequent. The importance of tremor in the diagnosis of Graves's disease is now established, and it is obvious that that affection was developing slowly when the mental impression produced by the operation precipitated its course. Exacerbations are not uncommon from the same cause, the thyroid enlarging and tremor and palpitation increasing under the influence of fear on sustained grief. I have notes of the case of a woman seen five years ago, in whom the affection was lighted up afresh by arduous nursing. It is noteworthy that, while tremor wae very marked in the original attack, it did not recur on the later occasion, though enlargement of the thyroid gland was prominent. Anything that conduces to nervous depression may originate or light up an attack. Unhealthy surroundings and insufficient food are not without result. Rendu records a case brought on by large doses of iodide of potassium, and Russell Reynolds believes that atmospheric conditions, such as low temperature, diminished rainfall, and diminished sunshine, may have some significance. These facts are suggestive in relation to the view revived of late years by Möbius that Graves's disease results from diseased activity of the thyroid gland. It seems to be generally accepted that this gland is a secreting organ which pours its juice through the lymphatics into the general circulation. Now, physiological teaching tends to show that secretion in general is diminished or arrested by emotional states and anything that lowers nerve force. Fear paralyses the action of the salivary glands, and the mental depression and slowing of the circulation induced by prolonged grief are more likely to dry up secretion than promote it. It is true, vaso-motor dilatation is determined by emotional states, but stimulation of the secretory nerves does not necessarily follow, and there may be obvious enlargement of the thyroid gland from vascular engorgement without increased secretion of thyroid juice. Prominence of the gland suggested its primary affection as the essence of Graves's disease, though there is the fact that goitre may come on with exophthalmos some months after other symptoms have set in, as the case quoted above shows; and, on the other hand, there may be enlargement of the thyroid gland long antecedent to any other departure from health. Certain facts give support to the idea that some of the symptoms at least may depend upon excessive secretion of the gland, and these are admirably set forth by Murray. In this relation the tremor first noted by Charcot, and the "rapid heart," are perbaps the most significant. Along with other nervous disturbances they have been noticed after large doses of thyroid extract. But, on the other hand, it is known that similar symptoms follow or are produced by loss of the thyroid gland. Horsley established the occurrence of muscular tremor and other nervous phenomena as the result of thyroidectomy in 